\title{
Discussion on current situation of green service area construction
}

\author{
Li Jian ${ }^{*}$, Jialin $\mathrm{Yao}^{1}, \mathrm{Xin}_{\mathrm{Meng}}^{2}$, Yangang Yang ${ }^{1}$, and Lei Guan ${ }^{1}$ \\ ${ }^{1}$ China Academy of Transportation Sciences, Beijing, 100029, China \\ ${ }^{2}$ Jilin Provincial High Class Highway Construction Bureau
}

\begin{abstract}
In the current period when the highway industry is accelerating the improvement of infrastructure construction and implementing new development concepts, the construction of green service area is an important part of promoting the high-quality development of highway transportation infrastructure. Based on the study of the connotation of the green service area, in order to provide experience and reference for its construction and transformation, this article put forward the content of the construction of green service area, and further combined the comprehensive survey of service areas of a certain province in central China, analysed and summarized current situation of green construction technologies from aspects of location and land use, buildings, environmental protection facilities, and renewable energy utilization.
\end{abstract}

\section{Introduction}

By the end of 2019, the total mileage of expressway in China has exceeded 140,000 kilometres, and the number of service areas has reached more than 3,000 pairs. Expressway service area is an important auxiliary facility of expressway, and its green construction is also an important part of the road industry in the new era to implement the concept of green transportation development and promote the high-quality development of highway transportation infrastructure [1]. However, for a long time, the construction level of service area has significantly lagged behind the main line project of the expressway, and its green construction has also started late. This not only caused many problems in energy conservation and environmental protection in the service area, but also seriously affected the service quality and function of expressway [2-5]. Under such circumstances and requirements, it is very necessary to conduct an indepth analysis and summary of the current status of green construction in the service area to provide a reference for the construction and transformation of the green service area in the future.

\section{Connotation analysis of green service area}

The essential characteristics of green development include low energy consumption, low material consumption, low emission, low pollution and sustainability, and these five aspects complement and promote each other. It also contains two important concepts of "needs" and "restrictions". Satisfying human needs is the main goal of sustainable development. Without this goal, "sustainability" is meaningless, but the satisfaction of needs must be limited within the carrying capacity of resources and environment.

In terms of green service area, it is necessary to provide drivers and passengers with high-quality, efficient, and complete transportation supporting services to meet the needs of service area development; at the same time, it must meet restrictive requirements to minimize resource occupation, energy consumption and ecological environment impact [6]. Therefore, a green service area can be defined as a service area that maximizes the protection of the environment, saves resources, reduces pollution, optimizes the landscape, and provides healthy, convenient and comfortable space for drivers and passengers during its whole life cycle.

\section{Main contents of green service area construction}

Based on the above-mentioned connotation of the green service area, its construction mainly considers the following five aspects:

Firstly, respect the original topography. Avoid largescale excavation for land levelling. Try to protect the surrounding mountains, water systems, and vegetation from disturbance. And maximize the protection of the surrounding ecological environment.

Secondly, improve the resources and energy supply capacity for the wholes system. Save the resources and energy consumption such as land, building materials, water, fuel and electric energy. Improve their utilization efficiency. And develop and utilize renewable energy as much as possible.

Thirdly, properly dispose of pollutants. Adopt effective technical measures to treat sewage, smoke, noise, garbage, and initial rainwater runoff from service area

\footnotetext{
a Corresponding author: 2410274917@qq.com
} 
operation, and reduce their pollution to an environmentally acceptable level.

Fourthly, optimize the landscape of the service area. Focus on the integration and coordination of the service area space and the surrounding natural environment. And pay attention to the protection and development of historical culture and traditional features.

Fifthly, improve functional facilities, such as specialty restaurants, leisure and entertainment facilities, information service systems, RV camps, etc., to meet the public's diversified and convenient travel needs.

\section{Analysis on the current situation of green construction of service area and applied technology}

In a province in central China, a survey on the current situation of green construction in more than 70 service areas was carried out using questionnaire combined with field investigation.

\subsection{Site selection and land use}

The construction of the service areas inevitably takes up a certain amount of land resources, which original function would be changed. And it is manifested in the conversion of non-construction land such as farmland, forest land, and grassland into transportation land. Therefore, the construction of green service areas should pay more attention to saving land resources. According to the survey, service areas built in the early stage lacked awareness of land resources protection, occupying large amount of land resources with high value. For an example, most of the service areas on an expressway have the same construction scale. At the beginning of the planning, the service areas of many road sections lacked in-depth demonstration of their status and role in the road network, road section traffic composition and service requirements, etc., resulting in low traffic volume after operation, and needlessly increasing the land occupation. Another example is that some expressway sections pass through cultivated land, and the service areas along the whole road were arranged in strict accordance with the spacing of 50 $\mathrm{km}$ attaching to the main line, resulting in some service areas occupying high valued cultivated land. In fact, appropriate and flexible consideration can be given to the spacing of service areas in this situation. Or the service areas could be selected within a certain range away from the main line. It is also advisable to make more use of barren hills and slopes, and to occupy as little cultivated land as possible. In addition, under the conditions of technically feasible, economic and reasonable, and meeting the requirements of operation and management, co-location of service areas with other stations, such as toll, monitoring and communication, and maintenance, is also a good way to save land resources.

In the service area site planning, the survey found that nearly $80 \%$ of the service areas are arranged in a doublesided, trapezoidal and symmetrical layout adjacent to the main line. However, if service areas are located in area with complex terrain conditions, such as a place near a mountain, in order to meet the regular trapezoidal layout, deep excavation, high filling, and large-scale land preparation are often adopted, resulting in environmental damage and huge energy consumption during construction. The service areas built in recent years have begun to attach importance to the ecological protection in the layout stage, and are no longer rigidly constrained to the traditional bilateral symmetrical layout, but adopt a flexible layout based on the original topography, natural waters, wetlands and vegetation distribution. Using layout methods such as the main line two-sided separation asymmetric type, the main line single-sided centralized type, and far away from the main line, etc., it could minimize the disturbance to the original ecology by avoiding the excavation of mountains, the separation of natural water bodies, and the destruction of forest vegetation. The service areas close to the mountain body adopted the form of cascade layout according to the terrain or the method of separating the functional areas by topography, avoiding the destruction of the original terrain by large filling and large excavation [7].

\subsection{Buildings}

The comprehensive service building is the most important building in the service area. It is responsible for providing comprehensive service functions such as toileting, dining, shopping, and indoor rest for drivers and passengers. Meanwhile, energy consumption of the comprehensive service building for lighting, heating, air conditioning and other services during its operation accounts for the main part of total energy consumption of service area. From the perspective of construction green service area, attention should be paid to the improvement of energy efficiency and service functions of buildings.

Generally, there is no shelter around the service area. Sunshine and monsoon will seriously affect the energy consumption of heating and air conditioning of buildings. The investigated province has hot summer and cold winter, with long winter and summer and short spring and autumn, leading to relatively large energy consumption of buildings. The survey found that the service area buildings, based on their own construction conditions, comprehensively adopted technical measures, such as envelope structure thermal insulation technology, installation of shading facilities, and design of openings conducive to natural ventilation and lighting, to reduce building energy consumption. Most comprehensive buildings have adopted more mature energy-saving materials, doors and windows, forming a maintenance structure with better thermal insulation performance. Many service areas use skylights in the lobby of the comprehensive service building to save electricity during the day; some service areas further optimize the skylight function, making it adjustable to be opened, which can fully introduce daylighting while effectively guiding natural ventilation. Some service areas' comprehensive service buildings set up external shading corridors at the entrances and exits, which not only form a soft transition and buffer function area between the parking lot and the 
building, but also an effective energy-saving measure for the building.

However, it is also found that the service areas lack flexibility in the rational layout of the building orientation, which leads to an increase in energy consumption. The comprehensive buildings surveyed are basically arranged parallel to the main line of the expressway. And $56 \%$ of these buildings are mainly north-south oriented with good natural lighting and ventilation conditions, which meet the requirements of suitable orientation for buildings in hot summer and cold winter areas. But orientation of the rest comprehensive service buildings is poor, 33\% east-west, and $11 \%$ northeast and northwest, leading to large energy consuming. In fact, the layout of the comprehensive service building can be flexible, and the main orientation can be selected to be suitable for energy saving, without being restricted by the direction of expressway main line. For example, when the main line runs north-south, the comprehensive service building can adopt a vertical main line layout through the coordination of site traffic organization and functional area deployment, and a suitable north-south orientation can be obtained.

In addition to energy saving, in recent years, the service areas that have been constructed and renovated have also made a lot of exploration in humanized design. For example, basically all these service areas have family toilets, which are fully equipped with barrier-free and children-only sanitation facilities to provide convenience for special groups. Public restrooms in service areas are often full during holidays, especially women's restrooms are more crowded. But if the flow of people during this period is used as the basis for restroom scale settings, it will cause a large amount of waste during common days. In response to this problem, some service areas have explored the use of tidal toilets. On the basis of optimizing the ratio of male and female toilets, by setting up facilities that can be adjusted conveniently, the male and female toilet spaces are flexibly divided during peak times, thus taking into account resource conservation as well as the needs of special periods.

\subsection{Environmental protection facilities}

Sewage and garbage treatment facilities are important supporting pollution prevention facilities in the service area, and their safe and reliable operation is the most basic requirement for the construction of green service areas. However, the survey found that the construction level of environmental protection facilities in the service area is still relatively backward, and the actual operation does not fully play a role in pollution prevention and control.

Nearly $80 \%$ of the sewage treatment facilities use buried integrated devices with contact oxidation as the main process unit. And the problem of excessive discharge of sewage is common during actual operation. On the one hand, it is because the sewage water quality and quantity of the service area vary greatly, and devices have poor resistance to impact load, resulting in unstable treatment effect. On the other hand, the sewage treatment facilities are simple in configuration with low level of automation of electromechanical equipment, and their operation are basically managed by the electrician in the service area on-site, meaning that they are in the blind operation stage. In fact, in recent years, there have been some advanced technological achievements focusing on the above-mentioned problems of sewage treatment in service areas, mainly in two directions: First is the use of biochemical and ecological combination of low energy consumption and low management treatment technology, making full use of ecological treatment technology such as artificial wetlands that have the advantages of strong impact resistance, simple operation and management, and stable water quality, and the discharge standards can be achieved in current situation where there is a lack of professional personnel to operate sewage treatment facilities. The second is to improve the automated operation level of sewage treatment facilities. By installing water quality online monitoring instruments, etc., the operation of the sewage treatment system can be remotely controlled by professionals to achieve professional and intensive operation and management.

In addition, the sewage produced from the service area can also be reused as reclaimed water after advanced treatment, which is conducive to the complete elimination of pollution and the saving and utilization of water resources. The service area must use domestic water for washing, dining and drinking, but other miscellaneous water such as toilet flushing, greening, road washing, etc. can be reclaimed. Because the water used for flushing in the service area is about $40-60 \%$, and the ratio of miscellaneous water is usually more than $70 \%$, a wellequipped reclaimed water reuse system can achieve the goal of saving water by $70 \%$ in the service area. However, the survey found that managers of service areas generally believe that water reuse is not economical. It is undeniable that the operating cost of sewage treatment and reuse facilities will be higher than discharging after treatment. However, in fact, comprehensively considering the cost of water extraction in the service area, the reuse of reclaimed water is still economical [8]: Firstly, water resource fees are saved. The groundwater resource fee of the surveyed province is about 1.2 yuan $/ \mathrm{m} 3$; for service areas that use municipal pipe network water supply, the water fee is as high as 3 to 4.5 yuan $/ \mathrm{m} 3$. If reclaimed water is used, the cost of water taking will be reduced. Secondly, electricity consumption of water taking is saved. In the investigated service areas in some severely water-deficient region, the water intake level of deep wells even reached to $400 \mathrm{~m}$ underground. And the electricity consumption for extracting $1 \mathrm{~m} 3$ of water to the original water tank on the ground is about $2 \mathrm{~kW} \cdot \mathrm{h}$, resulting in a cost of 1.4 yuan $/ \mathrm{m} 3$ water taking. Based on the above two factors, for service areas that use municipal pipeline network for water supply or deep well water intake, priority should be given to the construction of reclaimed water reuse systems.

Service areas generally attach importance to the classified collection of garbage, and the temporary storage after collection is regularly cleaned and transported by professional department. However, there are still shortcomings in the prevention and control of pollution in the temporary storage part. The survey found that $30 \%$ of the service areas still use open-air garbage pools to store garbage. Wind, sun and rain together breed mosquitoes 
and flies, and produce odours and leachate, causing a certain degree of secondary pollution. Although trash stations are built in other service areas, the supporting systems are not complete. In recent years, some pilot garbage stations in the service area have adopted airtight measures, setting up water supply pipelines equipped with flushing taps for ground cleaning and regularly disinfection. The flushing drainage into the sewage pipe network is treated by the sewage treatment facility in the service area to eliminate pollution.

\subsection{Renewable energy utilization}

Since the expressway service area having open space that satisfies the installation of photovoltaic modules for solar power generation systems and ground source heat pump systems, intensive use of land resources in the service area for renewable energy utilization is an important way to save energy. Since it was reported in 2012 that the China's first service area using solar photovoltaic power generation was completed, the application of this technology has been successively carried out in expressway service areas in different provinces. The independent photovoltaic systems built in the early stage use battery energy storage. Due to the high pollution and high energy consumption in the production and recycling of lead-acid batteries, and the effective power generated by photovoltaics being limited by the state of charge of the battery, these systems are rarely applied in recent years. Currently, the service areas basically use solar photovoltaic grid-connected power generation [9]. The electricity generated by the photovoltaic system is connected to the low-voltage side of the internal grid within the service area by means of $380 \mathrm{~V}$ low-voltage grid-connection. As soon as it is generated, it is used for local consumption of electric equipment in the service area, and the remaining electricity is supplied to the municipal power grid.

The surveyed province belongs to the third category of solar energy resources and are areas where solar energy resources can be developed and utilized. A total of 22 service areas have installed solar photovoltaic power generation systems. According to the province's subsidy policy for photovoltaic power generation, after comprehensive calculation, the photovoltaic on-grid electricity price is still far lower than the municipal electricity price. Therefore, from the perspective of investment recovery, the service area is not to expand the scale of the photovoltaic power generation system as much as possible, but to determine the photovoltaic installation capacity according to its own electricity load. The installed capacity of solar power generation in the 22 service areas range from 40 to $400 \mathrm{~kW}$. The photovoltaic panel array is laid on the roof of the building or above the parking space of the trolley to also provide shade. Taking a service area with an installed capacity of $390 \mathrm{~kW}$ as an example, a total of 1,560 polysilicon photovoltaic modules with power generation of $250 \mathrm{~W}$ are used. The total annual power generation of the system has reached $299,100 \mathrm{~kW} \cdot \mathrm{h}$, which is equivalent to saving $98.7 \mathrm{tce}$ of standard coal, and the energy saving effect is remarkable.
And $242000 \mathrm{~kW} \cdot \mathrm{h}$ electricity, which is $80.9 \%$ of the total photovoltaic power generation, is for the self-use of the service area, accounting for $53.1 \%$ of the total power consumption, indicating that more than half of the power consumption in the service area can be supplied by the renewable solar energy. In addition, the service area consumes a lot of electricity for air-conditioning and catering in summer. The monthly electricity consumption from June to September is relatively higher than that of other months. At this period, the photovoltaic power generation system is in high efficiency, providing more than $60 \%$ energy of the total electricity consumption in the service area. This eases the pressure on the municipal power grid from the service area to a large extent, which also shows that photovoltaic power generation provides a good seasonal "peak shaving" effect on the municipal electricity consumption in the service area.

The ground source heat pump (GSHP) system has complex process and high technical content, and its initial investment cost is much higher than that of conventional energy. To a certain extent, it inhibits the enthusiasm of the service area to use GSHP to replace traditional facilities. In recent years, under the guidance of policy, some service areas in the surveyed province have piloted the construction of GSHP systems. However, the survey found that managers from those service areas generally have low recognition of GSHP system, mainly complaining about the unstable heating and high energy consuming problems. In fact, conditions such as hydrogeology, engineering geology and geothermal field characteristics are the key to the successful application of GSHP systems. Before the system is applied, it is necessary to conduct detailed survey and calculation of shallow geothermal energy resources, and scientifically determine the detailed configuration of the heat pump system according to local conditions to ensure the heating effect after completion. In addition, the heat pump system is a complete set of units with relatively lower adjustment flexibility, comparing with split air conditioner. For some service areas with small traffic, the operating power consumption of the heat pump system may be higher than that of the split air conditioner. Therefore, the GSHP system is more suitable for application in service areas with large traffic and high air-conditioning utilization.

\section{Conclusion and suggestion}

In the current situation of the highway industry speeding up the improvement of infrastructure construction and implementing new development concepts, service area, as one of important auxiliary facilities of expressway, should continue to deepen the concept of green development and improve the construction level of green service areas. The construction of green service areas includes many aspects such as ecology protection, resources \& energy saving, pollution reduction, and facility functions improvement. And attention should be paid to overall planning and reasonable balance in actual engineering. To promote the construction of green service areas, it is necessary to apply appropriate green construction technologies according to local conditions and the characteristics of the service area 
projects. Based on the investigation of expressway service areas in a province in central China, this article analyses and summarizes the following conclusions:

(1) The site selection and land use of the service area should focus on saving land and protecting the ecology. Applying measures such as avoiding land idle by reasonably determining the scale of construction, flexibly selecting sites to occupy land with low resource value as much as possible, and co-building with other stations on the same site can help save land. The layout of the service area should be flexibly arranged according to the original topography, natural waters and vegetation distribution to reduce the disturbance to the original ecology caused by large-scale land preparation.

(2) The architectural design of the service area should pay attention to the improvement of energy conservation and service functions of buildings. The energy-saving performance of buildings can be improved by applying methods such as flexibly arranging the building orientation, adopting the thermal insulation technology of the envelope structure, setting up shading facilities, and design measures that are conducive to natural ventilation and lighting. And the improvement of building service functions should be promoted by strengthening humanized design.

(3) Environmental protection facilities in the service area are not operating well, so efforts should be made to improve their construction level. Sewage treatment facilities should adopt low-energy-consumption and easymanagement-maintenance treatment processes or implement professional and intensive operation and management mode to ensure that the discharge meets the emission standards. And qualified service areas should give priority to the construction of reclaimed water reuse systems. The garbage station should adopt airtight measures and be equipped with washing and disinfection facilities to eliminate pollution.

(4) The utilization of renewable energy in the service area should be adapted to local conditions. Solar photovoltaic grid-connected power generation system can be built in service areas with solar resource utilization conditions. Considering economic applicability, it is advisable to determine the photovoltaic installation capacity based on the service area's own electricity load. In order to fully display the energy-saving effect, GSHP system is more suitable for application in service areas with large flow of people and high air-conditioning utilization rate.

\section{Acknowledgments}

The work was supported by Science and Technology Demonstration Project of Ministry of Transport (No. 2017-04), Transport Science Project from Shandong Province (No. 2017B56), and Transport Science Project from Jilin Province (No. 2020-2-1).

\section{References}

1. Ministry of transport, Guiding opinions on the implementation of green highway construction, http://xxgk.mot.gov.cn/jigou/glj/201608/t20160803_ 2979321.html. (2016)

2. S. Shi, L.Q. Wan, S.Z. Jin, Hunan Communication Science and Technology, 037, 64 (2011)

3. J. Huang, Highway, 10, 222 (2019)

4. L. Jian, Highway Transportation Science and Technology (Application Technology Edition), 164, 319 (2018)

5. L. Yang, C.H. Mou, S.F. Wang, Highway, 5, 213 (2020)

6. Y.G. Yang, L. Jian, L. Guan, Transport Research, 5, 88 (2019)

7. L.L. Dong, L.P. Yang, H.Z. Yang, Highway, 11, 227 (2016)

8. L. Jian, J.L. Yao, X.P. Chen, Highway, 5, 199, (2016)

9. L. Jian, Y.G. Yang, Z.Y. Li, Highway, 2, 210 (2017) 